\title{
Effect of pile arrangement on the bending performance of an existing bridge footing under lateral seismic loading
}

\author{
Yong Yanga* (D) , Takahiro Masuda ${ }^{a}$ (D), Eiji Yoshida ${ }^{\text {(D) }}$, Satoshi Horiuchia (D), Takaharu Kiriyama ${ }^{a}$ \\ ${ }^{a}$ Center for Advanced Engineering Structural Assessment and Research, Public Works Research Institute, Tsukuba, Ibaraki, 305-8516, \\ Japan.Email: y-yang55@pwri.go.jp, masuda-t574bs@pwri.go.jp, e-yoshida@pwri.go.jp, horiuchi-s573bt@pwri.go.jp, kiriyama- \\ t673bs@pwri.go.jp \\ * Corresponding author
}

https://doi.org/10.1590/1679-78255913

\begin{abstract}
In this paper, to further understand the bending failure mechanism of a bridge footing subjected to lateral seismic loading, the effect of pile arrangement on the bending performance of a footing is mainly investigated by parametric analysis. The pile location can considerably affect the bending failure pattern of the footing by constraining the extent of yielding of footing top bars. The piles placed at the center of the sides parallel to the loading direction can constrain the extent of yielding of the top bars in the loading direction. Similarly, the piles at the center of the sides perpendicular to the loading direction can constrain the extent of yielding of the top bars in the other direction. The center pile can constrain the extent of yielding of the top bars in two directions. Additionally, based on the analytical results of the parametric analysis, the application condition of the current beam theory-based design method expected to accurately evaluate the footing bending capacity is discussed from the aspect of pile spacing.
\end{abstract}

\section{Keywords}

existing bridge footing; pile arrangement; bending failure pattern; parametric analysis; bending capacity

\section{Graphical Abstract}

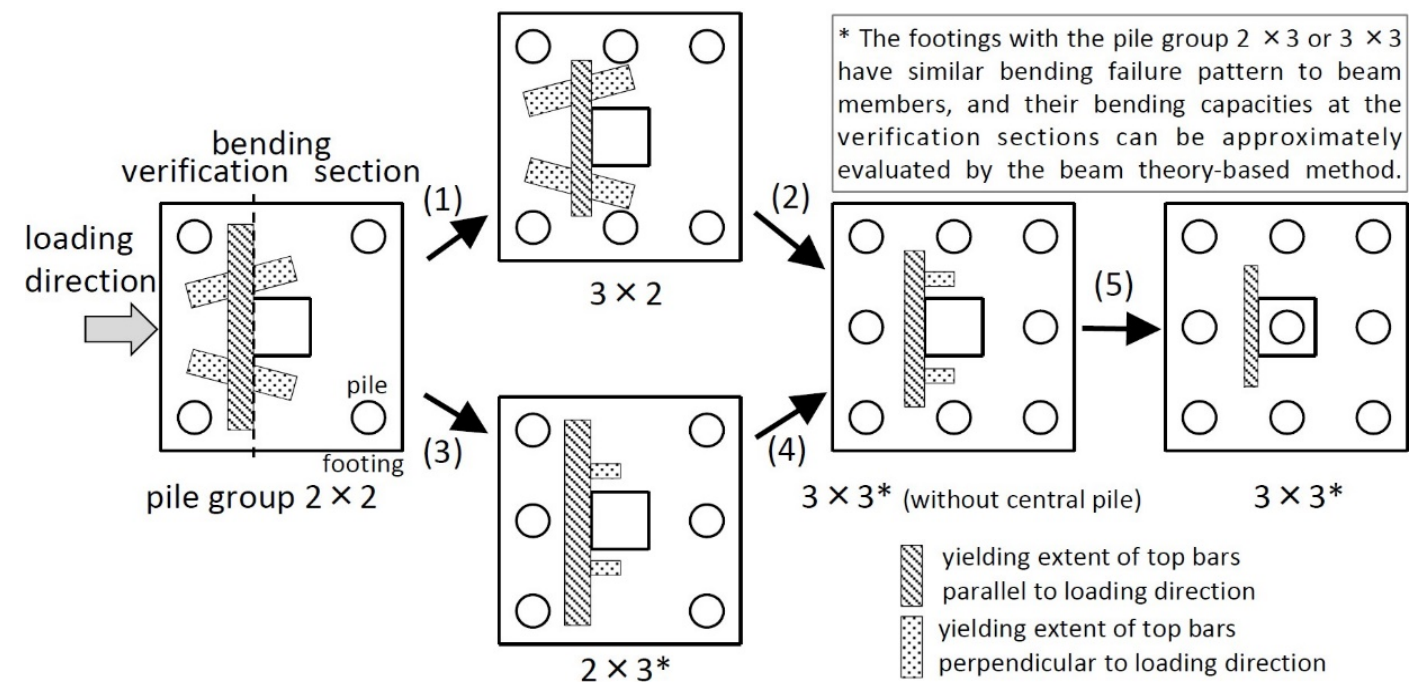




\section{Introduction}

During the 1995 Hyogo-ken Nanbu earthquake (Japan), the highway bridges designed with standards published before 1980 suffered from destructive damage (Kawashima and Unjoh, 1997), such as superstructure unseating and collapse. To prevent such types of destructive damage and ensure that relief activities run smoothly after an earthquake, a 3-year seismic retrofitting project was conducted from 2005 to 2007 targeting existing highway bridges on emergency transportation roads. In this retrofitting project, the bridge piers were mainly retrofitted, rather than bridge foundations. However, when the bridge piers are retrofitted with larger capacities than the bridge foundations, it is possible that bridge foundation failure will occur before bridge pier failure during future earthquakes. Figure 1 shows a damaged footing of a pile foundation, observed in an existing highway bridge with retrofitted piers after the 2016 Kumamoto earthquake (Japan). The bridge pier was severely inclined due to footing damage, and large repair construction was carried out. Thus, seismic performance evaluation and seismic retrofitting of bridge foundations of existing bridges, especially of those with retrofitted piers, is important.

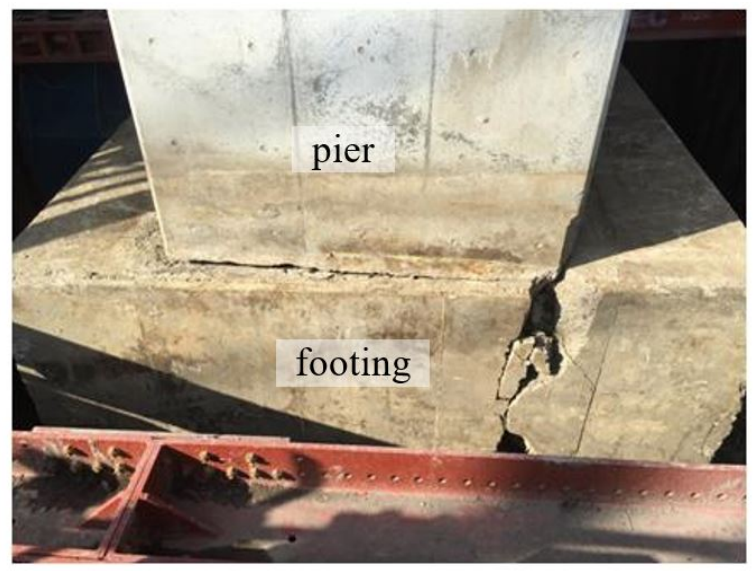

(a) earthquake-induced footing damage

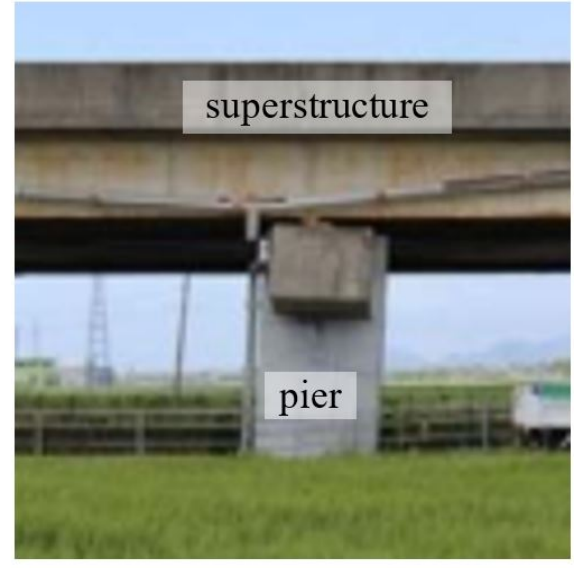

(b) inclined bridge pier due to footing damage

Figure 1: Footing damage of an existing bridge pile foundation in the 2016 Kumamoto earthquake (Japan).

For pile foundations most commonly adopted in existing bridges, footings are structural members that play a key role in the transfer path of a load from a superstructure to piles, and can largely affect the structural performance of bridge foundations. In the old design standards, footings are always considered to be beam members and mainly designed to bear vertical gravity loads. Previous studies also focused on investigating the structural performance of footings subjected to vertical gravity loads. For example, Clarke (1973) tested 15 four-pile-supported footings to study the influence of reinforcing bar layout and anchorage on the structural performance of the footing. Suzuki et al. (1999) tested 28 four-pile-supported footings with different longitudinal bar layouts and edge distances from the pile center to footing slab peripheral. Suzuki et al. (2001) tested 30 four-pile-supported footings with grid layout reinforcement to evaluate the edge distance effect on the structural behavior and strength of footings. Suzuki and Otsuki (2002) tested 18 four-pile-supported footings with grid reinforcement to examine the effect of anchorage type and concrete strength on the ultimate strength and failure mode of footings.

To more reasonably evaluate the load-carrying capacity of a footing under vertical loading, the design approach based on the strut-and-tie model has also been studied. For example, Adebar et al. (1990) reported the test results of six large pile-supported footings that failed in two-way shear and found that strut-and-tie models could accurately describe the structural behavior of a footing. Souza et al. (2009) proposed an analytical model based on the strut-and-tie approach and calibrated using an extensive experimental database from previous studies. The proposed model was proven to be applicable across a broad range of test data and to be able to predict the failures modes, cracking, yielding, and failure loads of four-pile footings with reasonable accuracy. To predict the shear strength of RC footings, Chetchotisak et al. (2017) proposed a new simple and practical strut-and-tie model, in which the concrete softening effect was taken into account. The validation of the proposed model was investigated using $110 \mathrm{RC}$ footing test results and other strut-and-tie models, and the results showed that the proposed model could give better accuracy and consistency. Other previous studies related to the strut-and-tie model can be found in the references (e.g., Adebar and Zhou 1996; Park et al. 2008; Bloodworth et al. 2012). In addtion, Jensen and Hoang (2012) proposed an upper bound plasticity approach for the strength prediction of reinforced concrete footings, and this approach can be considered a 
complement to the lower bound strut-and-tie model. Cao et al. (2019) also established a statically determinate two-way grillage model to solve the structure's shear capacity and confirmed that the proposed model could give more accurate and faster solutions than the tranditional strut-and-tie method and commerical nonlinear numerical modeling.

However, with regard to the structural performance of a footing under lateral seismic loading, which always leads to cracking and reinforcement yielding of the footing top, the relevant previous studies are very limited. For example, Xiao et al. (1996) conducted theoretical and experimental studies related to the seismic assessment and retrofitting of bridge spreading footings. To investigate the failure mechanism and bearing capacity of a footing subjected to lateral seismic loading, Kosa et al. (1999) tested a four-pile-supported footing, designed based on a prototype bridge footing damaged in the 1995 Hyogo-ken Nanbu earthquake. To further investigate the seismic behavior of footings, Kosa et al. (2000) tested 3 four-pile-supported footings with different shear span ratios and reinforcement ratios. Xiao et al. (2011) carried out the loading tests to investigate the seismic behavior of the column and pile-footing models with different column-to-footing connections, under a vertical cantilever condition with cyclic horizontal forces and a constant axial load. In addition, the seismic behavior of the pile-to-footing connections or the column-to-footing connections was also investigated by the loading tests in precious studies (Shama et al. 2002; Xiao et al. 2006; Xiao and Chen 2013; Haber et al. 2014; Ameli et al. 2016; Kappes et al. 2016; Grilli et al. 2017).

Furthermore, in most design standards, such as the Design Specifications for Highway Bridges of Japan (Japan Road Association, 2017), the footing in a new bridge design is approximately considered as beam member and always designed based on the engineering beam theory-based method for seismic loads. Although the engineering beam theory-based method is very easily used for footing design, it cannot sufficiently describe the footing structural behavior and always leads to conservative evaluation results. The application scope of the beam theory-based method is also unclear. A previous study conducted by Kosa et al. (1999) showed that the bearing capacity of a footing measured in a loading test was about two and half times that evaluated via the beam theory-based method. However, for the numerous existing bridges, it is significantly important to accurately evaluate the seismic performance of existing footings to reasonably prioritize the seismic retrofitting. It is very different from the footing design of new bridge.

To development the new evaluation method for footing seismic performance, it is necessary to first clarify the failure mechanism of a footing subjected to seismic loading, which has not yet been well understood in previous studies. In this paper, the effect of pile arrangement on the bending failure pattern of a footing subjected to lateral seismic loading, which is not considered in the current beam theory-based design method, is mainly investigated as a complement to previous studies. First, a footing static loading test, which was conducted at the Public Works Research Institute of Japan, is introduced and a finite element (FE) analysis is conducted to obtain the basic model for parametric analysis of the pile arrangement effect. Second, based on the basic model, the parametric analysis is carried out to investigate the effect of pile arrangement on the footing bending failure pattern under seismic loading. Third, based on the analytical results of the parametric study, the application conditions of the current beam theory-based design method expected to accurately evaluate the bending capacity is discussed from the aspect of pile spacing.

\section{Review of experimental work}

\subsection{Footing specimen}

With reference to prototype bridges designed with old standards published before 1980 in Japan, the 1/3 scale four-pile-supported footing specimen shown in Figure 2 was designed. Further information about the similarity laws between the scaled-down model and prototype can be found in the references (e.g., Casaburo et al. 2019; Coutinho et al. 2016). The footing portion has dimensions of $2500 \mathrm{~mm} \times 1600 \mathrm{~mm} \times 650 \mathrm{~mm}$. The pier portion has cross-sectional dimensions of $600 \mathrm{~mm} \times 600 \mathrm{~mm}$ and height of $1550 \mathrm{~mm}$. The pile portion has a diameter of $350 \mathrm{~mm}$ and length of $300 \mathrm{~mm}$. Piles with shorter lengths are used to simulate the reaction force distribution of the pile foundation.

The top reinforcement of the footing portion is 8 bars of D13 parallel to the long side and 14 bars of D13 parallel to the short side; the bottom reinforcement is 16 bars of D19 parallel to the long side and 26 bars of D19 parallel to the short side, respectively. Parallel to the long side of the footing portion, the ratios of the steel area to footing cross-sectional area are $0.11 \%$ at the top and $0.49 \%$ at the bottom. The longitudinal reinforcement of the bridge pier is 24 bars of D32. The transverse reinforcement of the bridge pier is D19 with a spacing of $50 \mathrm{~mm}$. In each pile, the longitudinal and transverse reinforcements are 14 bars of D25 and D13 with a spacing of $50 \mathrm{~mm}$, respectively. In addition, the measured material properties of the steel bars and concrete are shown in Table 1a-1b, respectively.

During the loading test, the four piles of the footing specimen were fixed to a strong reaction floor. To simulate the dead weight of the bridge superstructures, a vertical force of $600 \mathrm{kN}$ was applied by pulling the lower end of a steel 
rod placed inside the bridge pier. A monotonic loading was applied in the horizontal direction by an actuator at a height of $1 \mathrm{~m}$ from the top of the footing.

Further information about the footing specimen can be found in a technical note of the Public Works Research Institute (2015).

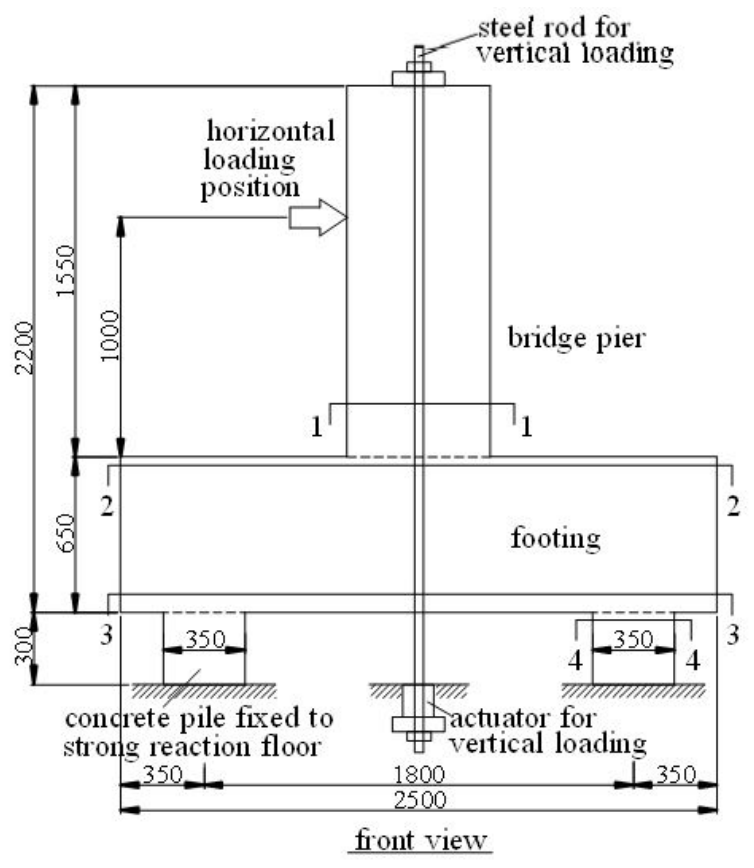

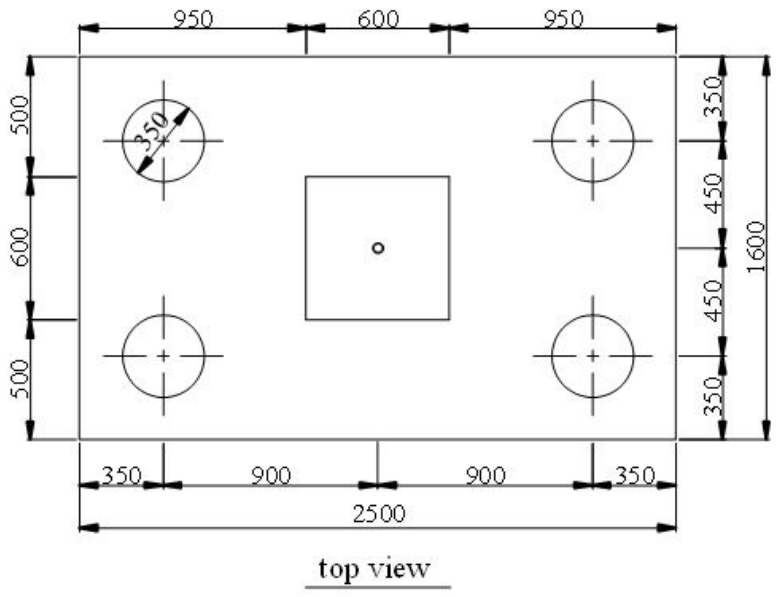

(a) dimension details

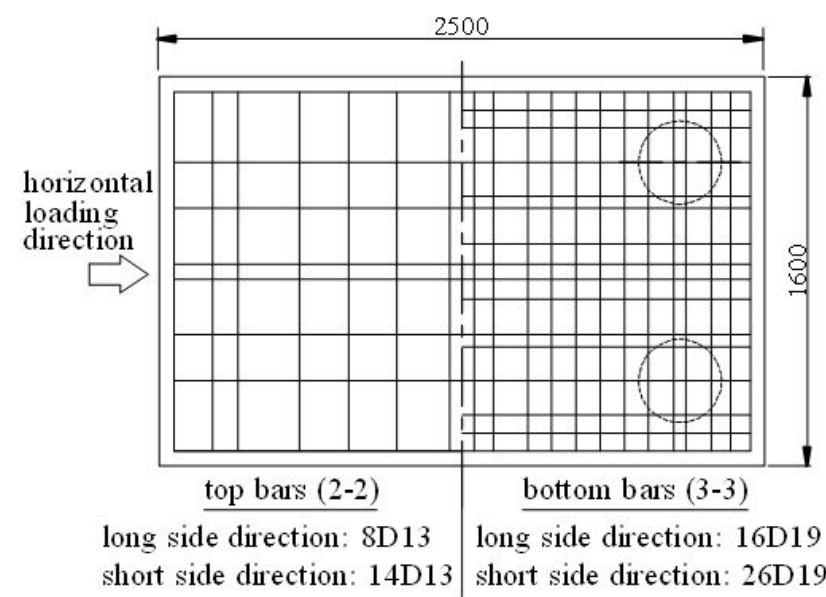
reinforcing bars of footing

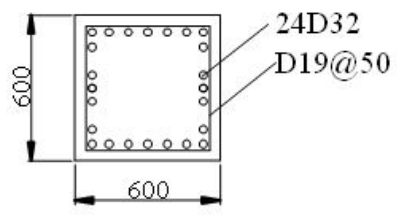

$14 \mathrm{D} 25$ D13@50

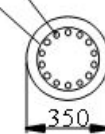

reinforcing bars of pier (1-1) reinforcing bars of pile (4-4)

Figure 2: Details of footing specimen (unit: $\mathrm{mm}$ ).

Table 1a Material properties: Reinforcing bars

\begin{tabular}{ccccc}
\hline & nominal diameter $(\mathbf{m m})$ & elastic modulus $\left(\mathbf{N} / \mathbf{m m}^{2}\right)$ & yield strength $\left(\mathbf{N} / \mathbf{m m}^{2}\right)$ & tensile strength $\left(\mathbf{N} / \mathbf{m m}^{\mathbf{2}}\right)$ \\
\hline D13 & 12.7 & $1.94 \times 10^{5}$ & 397.3 & 584.1 \\
D19 & 19.1 & $1.95 \times 10^{5}$ & 364.7 & 584.1 \\
D25 & 25.4 & $1.94 \times 10^{5}$ & 405.2 & 595.0 \\
D32 & 31.8 & $1.97 \times 10^{5}$ & 372.7 & 557.0 \\
\hline
\end{tabular}

Table $1 b$ Concrete

\begin{tabular}{ccc}
\hline & elastic modulus (N/mm $\left.{ }^{2}\right)$ & compressive strength (N/mm $\left.{ }^{2}\right)$ \\
\hline footing and pile & $2.42 \times 10^{4}$ & 32.4 \\
pier & $2.30 \times 10^{4}$ & 27.8 \\
\hline
\end{tabular}




\subsection{Main experimental results}

The horizontal force-displacement relationship at the loading position is shown in Figure 3. Along with the yielding of the footing top bars ((1) and (2)) placed in the loading direction at the bending verification section, the horizontal rigidity of the footing specimen obviously decreased. After the yielding of the longitudinal bars of the pier $((3))$, the loading test was terminated due to insufficient actuator capacity ((4)). Considering that the footing top bars reach a complete yielding status $((2))$, reloading was not carried out; thus, there is no deceasing stage shown in the horizontal force-displacement curve. Based on the axial strain of the steel rod measured during the loading stage, which considerably increased near the point of maximum horizontal force, it is believed that the steel rod served as tension reinforcement to improve the pier capacity during the loading test, resulting in the maximum horizontal force of footing specimen exceeding the selected actuator capacity.

The recorded crack distribution on the surface of the footing portion at the point of maximum horizontal force is shown in Figure 4. The damage near at the bending verification section is considerably greater than that at the other locations.

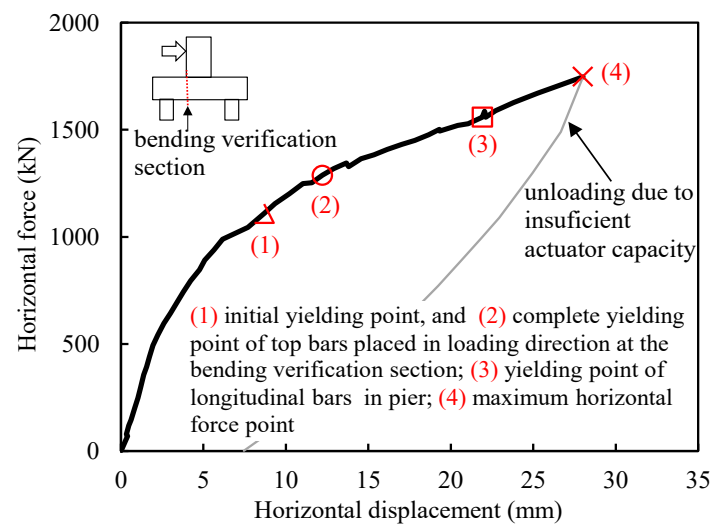

Figure 3 Horizontal force-displacement relationship at the loading position

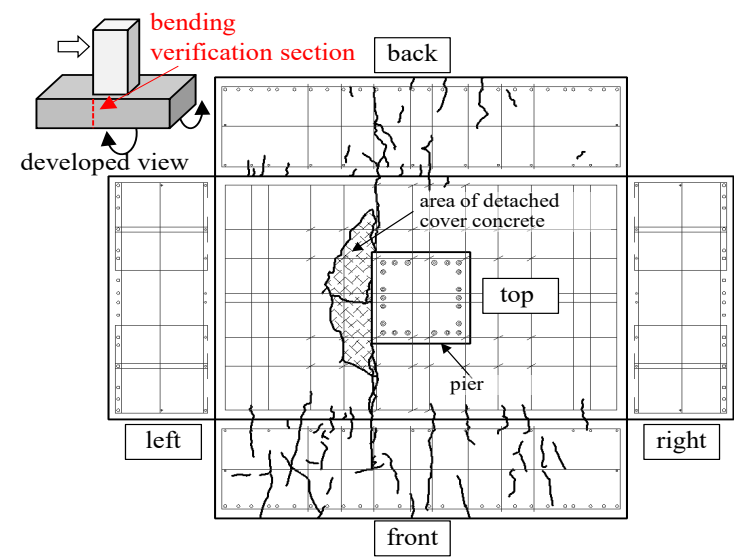

Figure 4: Footing crack distribution at the point of maximum horizontal force.

\section{Development of the basic model for parametric analysis}

\subsection{Description of the basic model}

The basic model for the parametric analysis carried out in Section 4 is developed based on the FE analysis of the loading test, using the program DIANA (TNO DIANA BV, 2018). The overall geometry of the basic model shown in Figure 5 is identical to that of the experimental specimen (Figure 2). An eight-node isoparametric solid brick element (HX24L in DIANA) is chosen to model the concrete. Based on the preliminary analysis, the mesh size of the concrete element is determined to be $50 \mathrm{~mm}$. The tensile constitutive model of the concrete material proposed in the references (Cornelissen et al., 1986; Hordijk, 1991) considering tension softening is used. The parabolic curve with a formulation based on fracture energy (Feenstra, 1993) is adopted for the concrete compressive constitutive model. The reinforcing steels are modeled as embedded bar elements in DIANA and assumed to be elasto-plastic, considering 
the strain hardening effect. The fixed boundary conditions are applied at the lower end of the piles, as in the loading test.

The vertical force acting on the pier top is simulated by a distributed force, with a resultant force equal to the applied vertical force in the loading test. A horizontal force acting at the same position as that in the loading test is simulated by a displacement-controlled method.

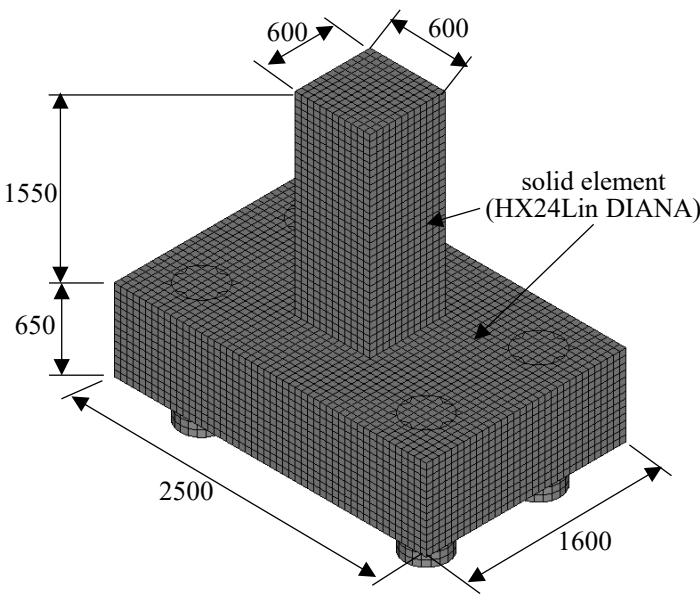

Figure 5: FE model (unit: $\mathrm{mm}$ ).

\subsection{Verification of the basic model with the experimental results}

The comparison of the horizontal force-displacement relationship between the FE analysis and the experimental results is shown in Figure 6. The FE analysis results show good agreement with the experimental results nearly throughout the loading stage. Since the steel rod is not modeled and there is no effect on the pier section capacity, the FE analysis result truly reflects the capacity deterioration of the pier section.

At the point of maximum horizontal force, regarding the FE analysis result, the principal tensile strain on the top face of the footing concrete and axial tensile stress of the top bars of the footing are shown in Figures 7 and 8 , respectively. The principal tensile strain of the footing concrete near the bending verification section is obviously larger than that at other locations, consistent with the crack distribution of the experimental result (Figure 4). The axial tensile stress of the footing top bars also shows a similar distribution trend to that of the principal tensile strain of the footing concrete.

Thus, the FE model can accurately predict the overall behavior of a footing specimen and is used as the basic model for the following parametric analysis related to the pile arrangement effect.

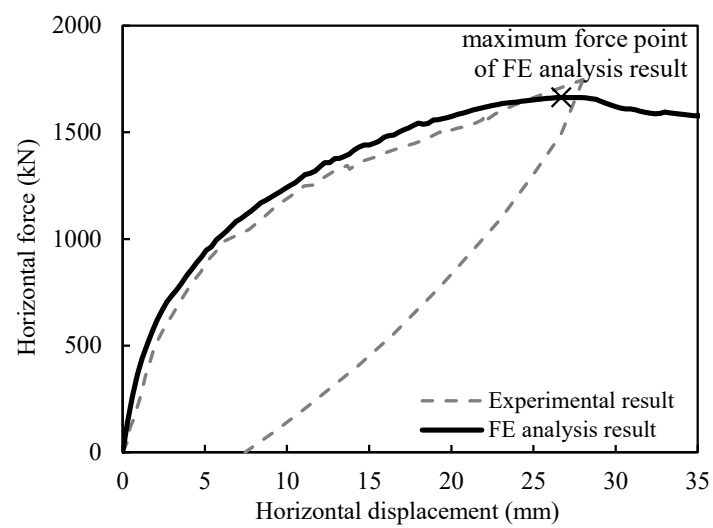

Figure 6: Comparison of the horizontal force-displacement relationships between the FE analysis and the experimental results. 


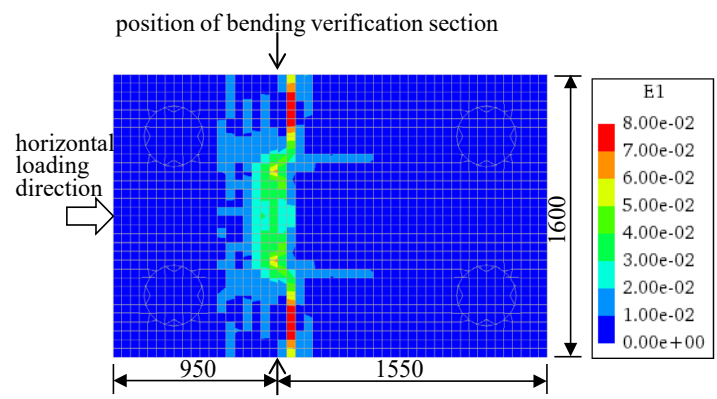

Figure 7: Principal tensile strain on the top face of footing concrete at the point of maximum horizontal force.

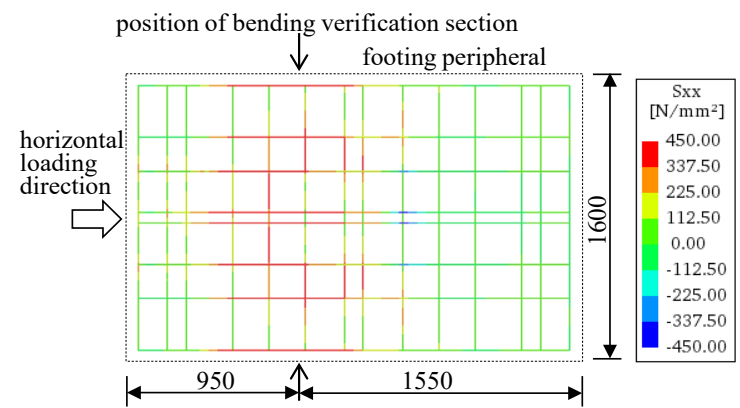

Figure 8: Axial tensile stress of footing top bars at the point of maximum horizontal force (yield strength: $397.3 \mathrm{~N} / \mathrm{mm}^{2}$ ).

\section{Parametric analysis of the pile arrangement effect}

\subsection{Parameter setting of the pile arrangement}

In the current beam theory-based method (Japan Road Association, 2017) to evaluate the footing bending capacity, the footing is simply considered as beam member and assumed to have the similar bending failure pattern, without considering the pile arrangement effect. Via a parameter analysis, the effect of piles at different locations on the footing bending failure pattern is investigated.

As shown in Figure 9, two series of footing models are set with different side lengths. In Series 1, with a side-length ratio equal to $0.64\left(L_{1} / L_{2}=1600 / 2500\right)$, the basic model verified in Section 3 is designated as Case S1-1; Case S1-2 is developed to study the effect of piles placed at the center of the sides parallel to the loading direction on the footing bending damage pattern.

Due to the short length of the side perpendicular to the loading direction in the basic model Case S1-1, no more piles can be placed without creating a spacing less than two and half times the pile diameter, as prescribed in the design standard (Japan Road Association, 2017), to consider the pile group effect. Thus, based on the basic model, the models included in Series 2 are developed with longer sides perpendicular to the loading direction, resulting in a larger side-length ratio equal to $1.04\left(L_{1} / L_{2}=2600 / 2500\right)$. In Series 2 , Cases S2-1 to $S 2-4$ are developed to study the effect of piles placed at the center of not only the sides parallel to the loading direction but also the sides perpendicular to the loading direction. Case S2-5 studies the effect of a pile at the center of the footing on the footing bending damage pattern.

To easily investigate the pile arrangement effect, the footings of the cases included in two series have the same height as that of the basic model. The footing steel ratios at both the top and bottom in two directions are also equal to these of the basic model. In addition, the piles in these cases have the same dimension and reinforcement details. The piers in these cases also have the same details. Furthermore, the vertical forces acting on the piers in these cases are made equal to easily investigate the pile arrangement effect. 


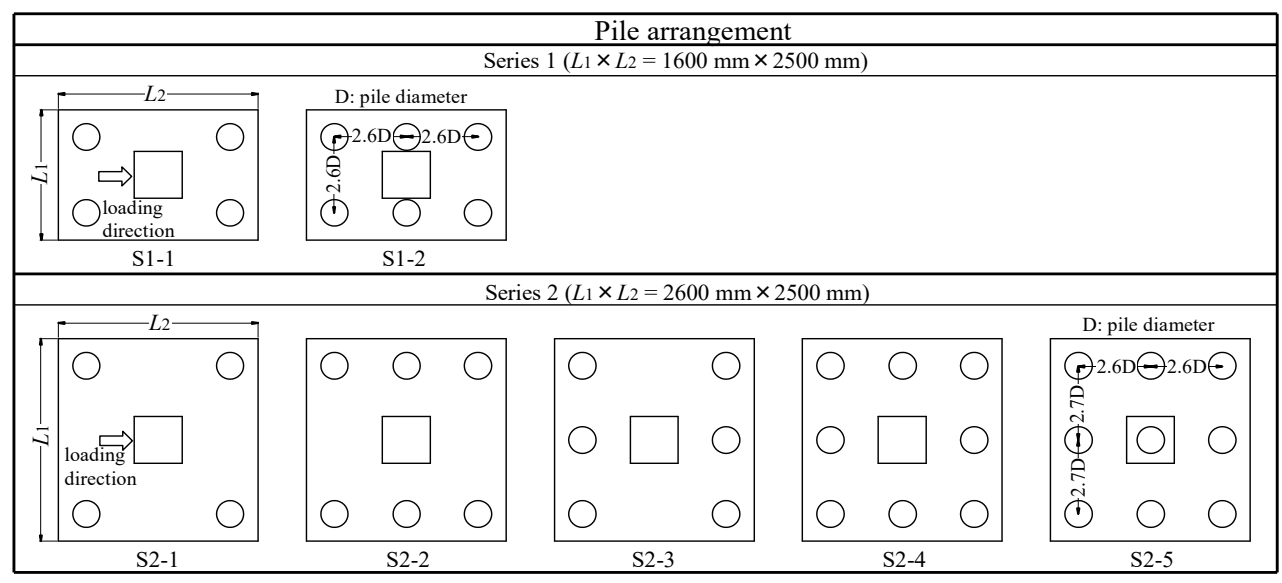

Figure 9: Parameter setting of the pile arrangement.

\subsection{Effect of pile arrangement on the horizontal force-displacement relationship of the footing}

The FE analysis of the footing models, shown in Figure 9, for the parametric study is carried out under the same analysis settings as that of the basic model described in Section 3.1. The FE analysis results of the horizontal force-displacement relationships at the loading position are shown in Figure 10.

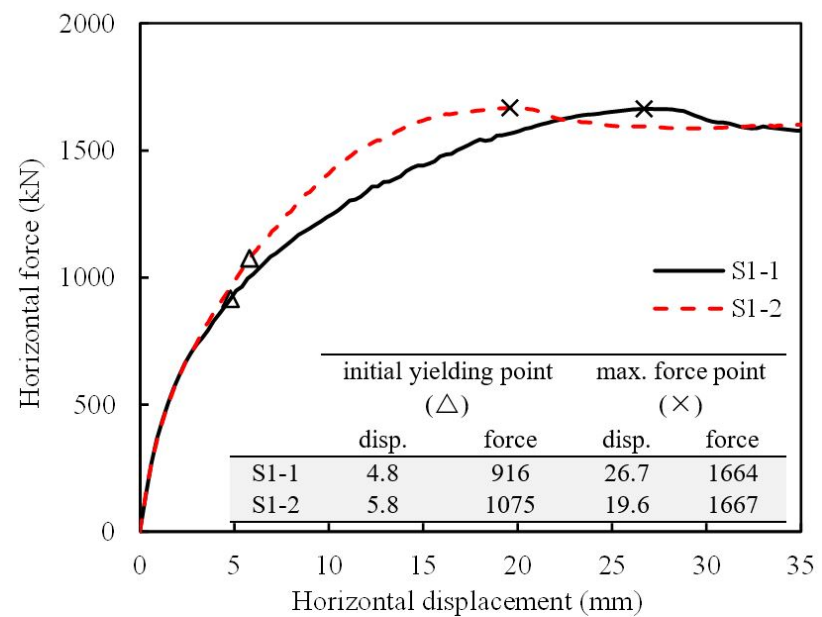

(a) series 1

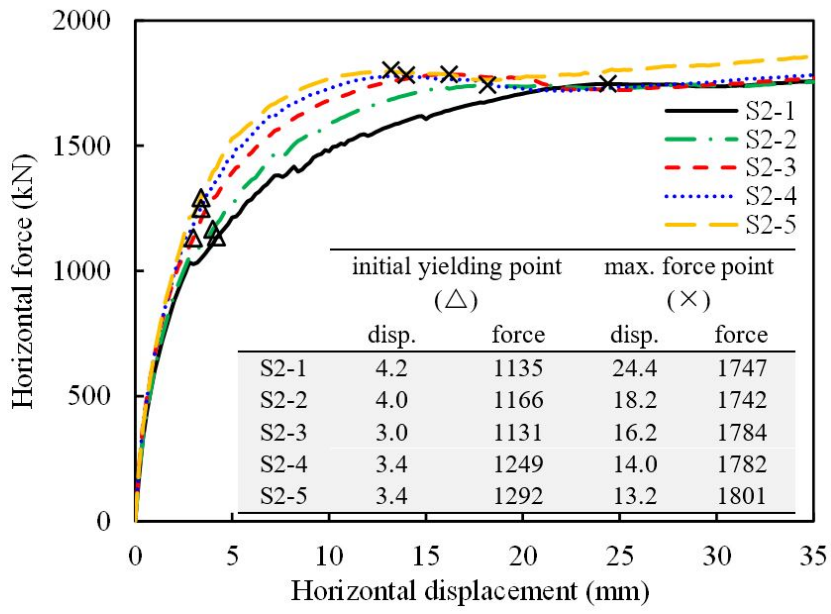

(b) series 2

Figure 10: FE analysis results of the horizontal force-displacement relationships.

As shown in Figure 10, in Series 1, before the initial yielding of the footing top bars placed in the loading direction, the addition of two piles at the center of sides parallel to the loading direction has little effect on the force-displacement relationship. However, after the initial yielding, Cases S1-2 has larger horizontal rigidity than that of Case S1-1, showing the effect of the additional two piles. Thus, Case S1-2 has a larger horizontal force than that of Case S1-2 after the initial yielding, although the maximum horizontal forces in Cases S1-1 and S1-2 are almost identical, as determined by the longitudinal bars yielding in the pier.

Since a large amount of footing reinforcement is included in the cases of Series 2 to obtain a reinforcement ratio equal to that of Series 1, the piers in Series 2 are modeled with rigid elastic material, to ensure the sufficient development of footing reinforcement yielding. Thus, the maximum horizontal force of each case in Series 2 is determined by the footing instead of the pier. Each case of Series 2 has approximately the same maximum horizontal force, which is controlled by the compressive failure of the footing. However, before the point of maximum horizontal force, Series 2 exhibits similar results of the force-displacement relationships to Series 1 . That is, the pile arrangement can affect the force-displacement relationship after initial yielding. In particular, in Cases S2-2 and S2-3 with the same pile number, the force-displacement relationship of Case S2-3 is obviously different than that of Case S2-2, indicating that pile location is an important parameter affecting the structural performance of a bridge foundation. When the 
piles are placed at the center of the sides perpendicular to the loading direction, the horizontal rigidity of the bridge foundation can be effectively improved.

\subsection{Effect of pile arrangement on the bending failure pattern of the footing}

Figure 11 shows the extent of yielding of footing top bars at the point of maximum horizontal force for each case included in Series 1 and 2, respectively. The results show that the footing bending failure pattern largely depends on the pile arrangement. This finding can be explained by the change in the distribution of the pile reaction forces (Figure 12). Based on these analysis results, the effect of the piles at different locations on the bending failure pattern of the footing are discussed as follows.

\subsubsection{Piles at the center of the footing sides parallel to the horizontal loading direction}

In Cases S1-1 and S1-2 of Series 1, as shown in Figure 11(a) and (b), at the point of maximum horizontal force, all the top reinforcing bars placed in the loading direction reach the yielding state at the location near the prescribed bending verification section. However, Case S1-1 exhibits a larger yielding extent than that of Case S1-2, in which the additional two piles are placed at the center of the sides parallel to the horizontal loading direction, although Cases S1-1 and S1-2 sustain approximately the same maximum horizontal force (Figure 10). In other words, the extent of yielding of the top bars in the loading direction in Case S1-2 is constrained by the additional two piles. This finding can be explained by the change in the reaction forces of the tensile piles. As shown in Figure 12, due to the effect of the piles placed at the center of the sides parallel to the horizontal loading direction, Case S1-2 exhibits lower vertical reaction forces than those of Case S1-1. At the point of maximum horizontal force, the sum of the vertical reaction forces of the tensile piles 1 and 2 in Case S1-1 is 1324 kN; however, in Case S1-2, the sum of the vertical reaction forces decreases to $770 \mathrm{kN}$. Thus, the moment acting on the bending verification section in Case S1-2 is smaller than that of Case S1-1. Consequently, in Case S1-2, the footing top bars in the loading direction reach the yielding state later than those in Case S1-1 do, resulting in a smaller extent of yielding at the maximum force point.

In Cases S2-1 and S2-2, although the footing top bars placed in two directions yield with a large extent at the maximum force point (Figure 11(c) and (d)), showing a different yielding behavior from that of Series 1, the effect of the piles located at the center of the sides parallel to the loading direction on the footing bending failure pattern can be similarly confirmed. The extent of yielding of the top bars placed in the loading direction in Case S2-2 is obviously constrained by the additional two piles, compared with that of Case \$2-1. This finding also can be explained by the change in vertical reaction forces in the tensile piles shown in Figure 12(c) and (d).

Furthermore, in Cases S2-3 and S2-4, which have different pile arrangements from that of Cases S2-1 and S2-2, the effect of piles at the center of the sides parallel to the loading direction can also be confirmed (Figure 11(e) and (f)). The change in vertical reaction forces in the tensile piles, which cause the change of the extent of top bar yielding, is shown in Figure 12(e) and (f).

\subsubsection{Piles at the center of the footing sides perpendicular to the horizontal loading direction}

For Cases S2-1 and S2-3, the extents of yielding of the footing top bars at the point of maximum horizontal force are obviously different from each other (Figure 11(c) and (e)). By placing the additional two piles at the center of the sides perpendicular to the horizontal loading direction, the extent of yielding of the top bars perpendicular to the horizontal loading direction is constrained in Case S2-3. This finding also can be explained by the change in the vertical reaction forces in the tensile piles. As shown in Figure 12(c) and (e), although the sums of the vertical reaction forces of the tensile piles are almost identical, the vertical reaction forces of the corner tensile piles, which can affect the extent of yielding of the top bars perpendicular to the horizontal loading direction, is greatly decreased from $657 \mathrm{kN}$ in Case S2-1 to $235 \mathrm{kN}$ in Case S2-3. Thus, the moment acting on the section parallel to the loading direction is decreased, resulting in the smaller extent of yielding of the top bars perpendicular to the horizontal loading direction in Case S2-3.

For Cases S2-2 and S2-4, the effect of the piles at the center of the side perpendicular to the loading direction on the extent of yielding of the top bars is similarly confirmed (Figure 11(d) and (f)). This finding also can be explained by the change in the vertical reaction forces in the tensile piles (Figure 12(d) and (f)).

\subsubsection{Pile at the center of the footing}

As shown in Figure 11(f) and (g), compared with Case S2-4, the extents of yielding of the footing top bars in two directions in Case S2-5 are constrained by the pile placed at the footing center. This difference can be explained by the change in the vertical reaction forces in the tensile piles. As shown in Figure $12(\mathrm{f})$ and $(\mathrm{g})$, the sum of the vertical reaction forces in tensile piles 1 to 3 , which can affect the extent of yielding of the steel bars parallel to the loading 
direction, is decreased from $953 \mathrm{kN}$ in Case S2-4 to $853 \mathrm{kN}$ in Case S2-5; the sum of the vertical reaction forces in tensile piles 1 and 4, which can affect the extent of yielding of the bars perpendicular to the horizontal loading direction, is decreased from $513 \mathrm{kN}$ in Case S2-4 to $374 \mathrm{kN}$ in Case S2-5. Consequently, the extents of yielding of the footing top bars are constrained in two directions in Case S2-5.

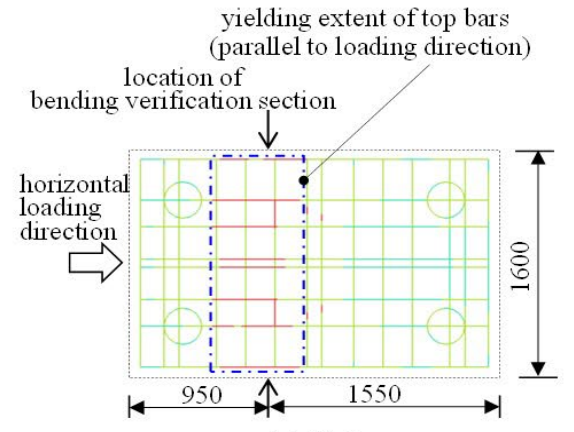

(a) S1-1

yielding extent of top bars (perpendicular to loading direction)

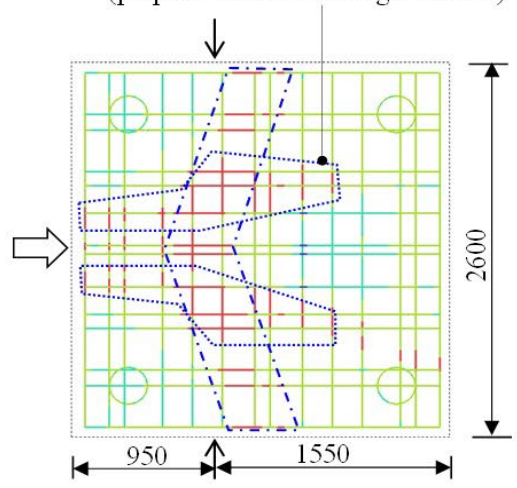

(c) S2-1

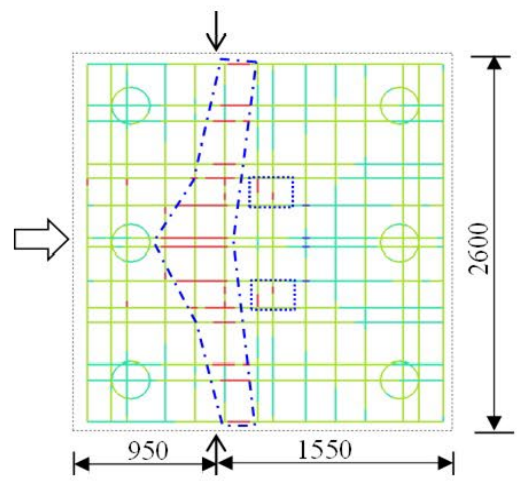

(e) S2-3

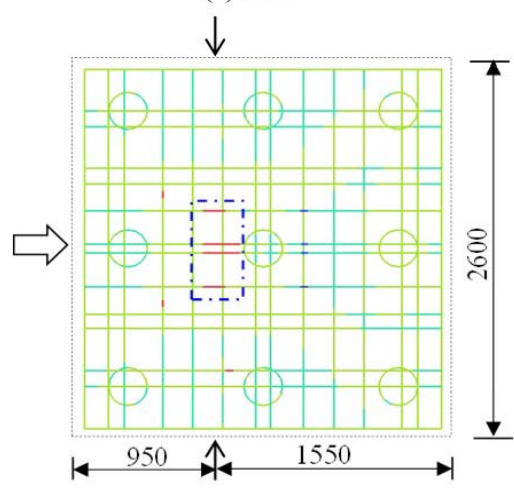

(g) S2-5

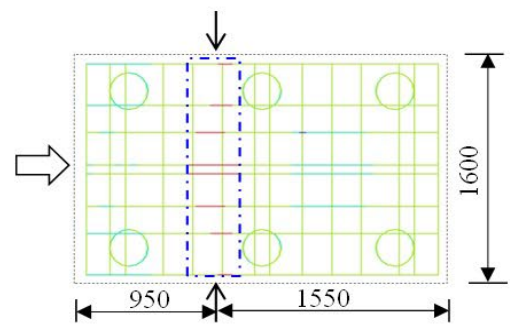

(b) $\mathrm{S} 1-2$

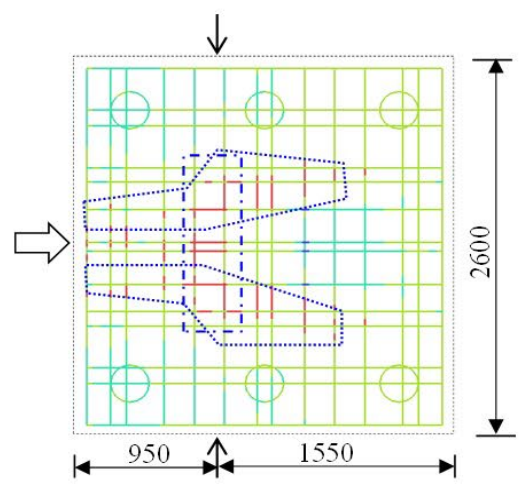

(d) S2-2

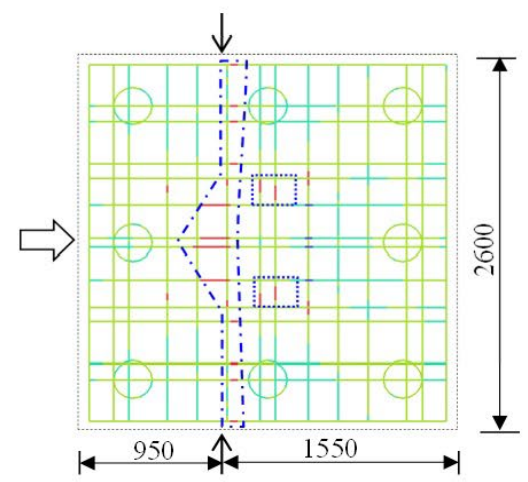

(f) $\mathrm{S} 2-4$

Figure 11: Extent of yielding of the top bars at the point of maximum horizontal force. 


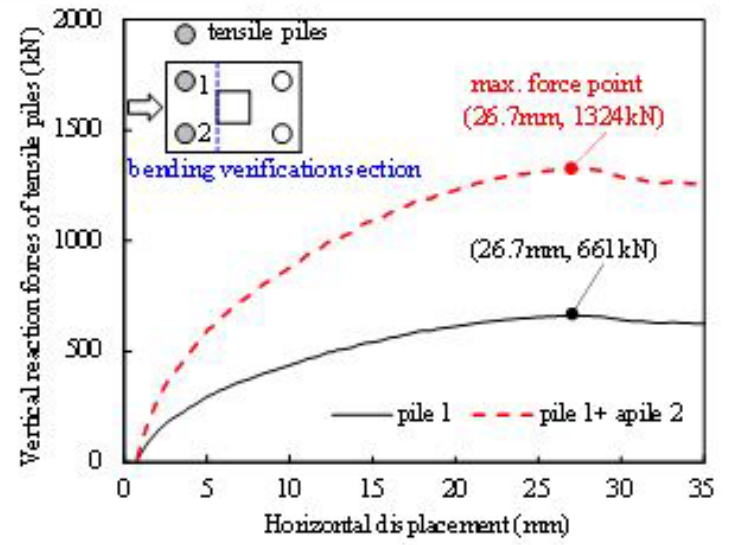

(a) $\mathrm{S} 1-1$

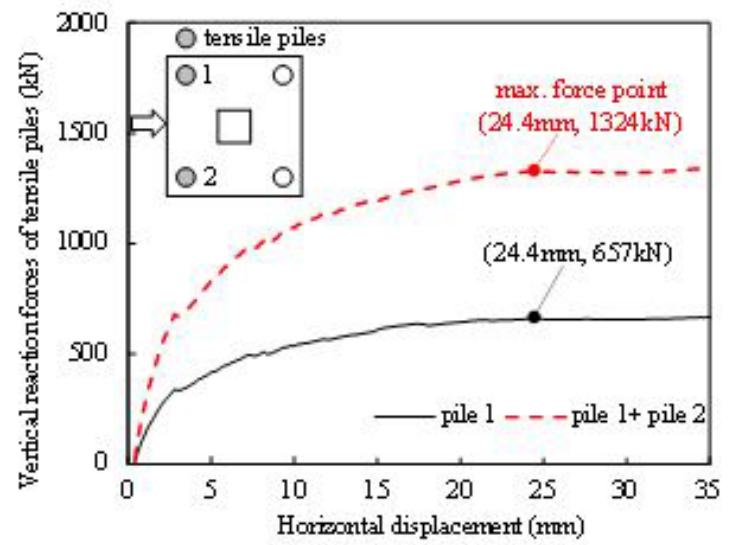

(c) $\mathrm{S} 2-1$

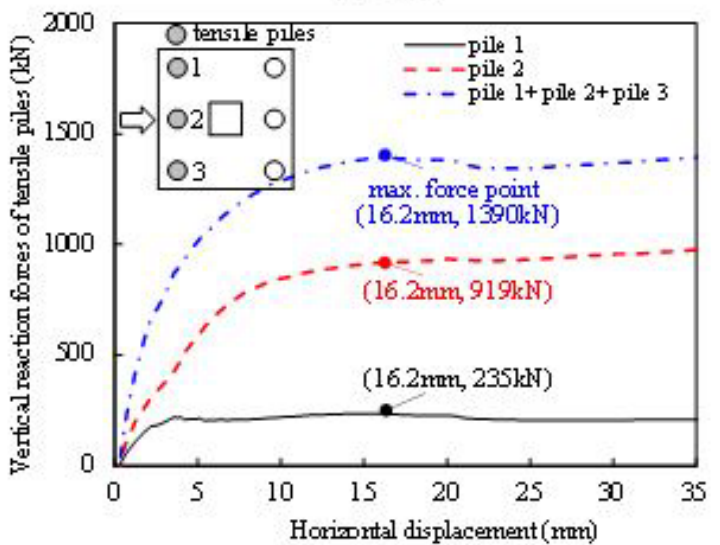

(e) $\mathrm{S} 2-3$

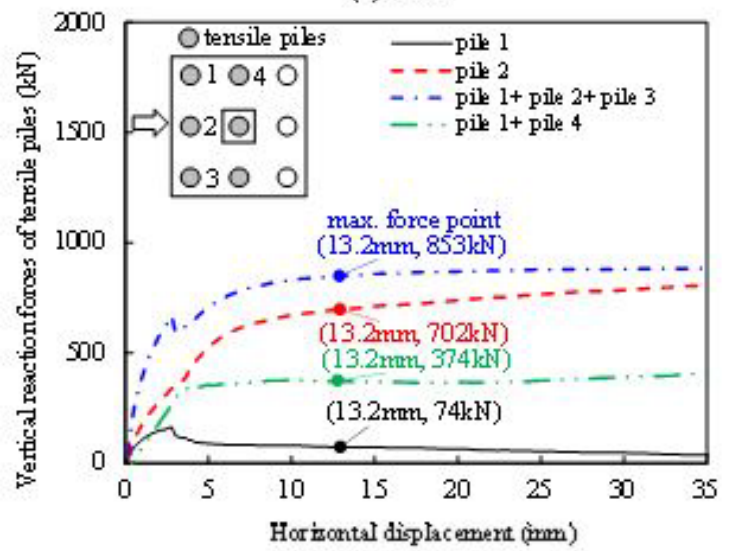

(g) $\mathrm{S} 2-5$

Figure 12: Vertical reaction forces of the tensile piles force.

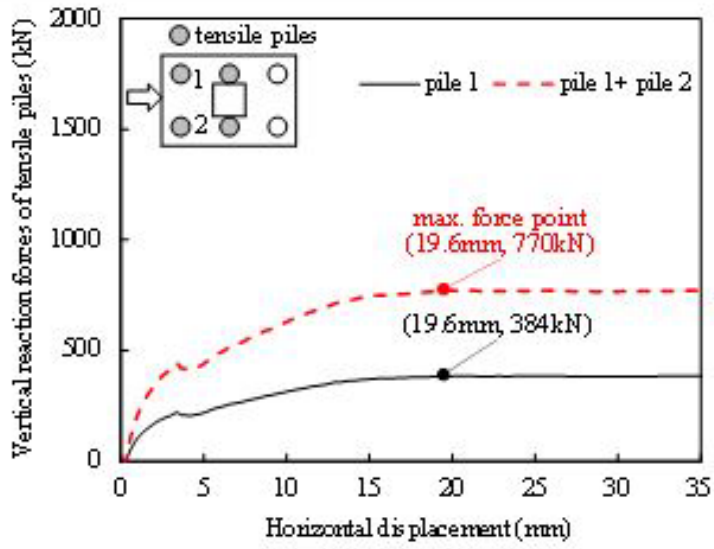

(b) $\mathrm{S} 1-2$

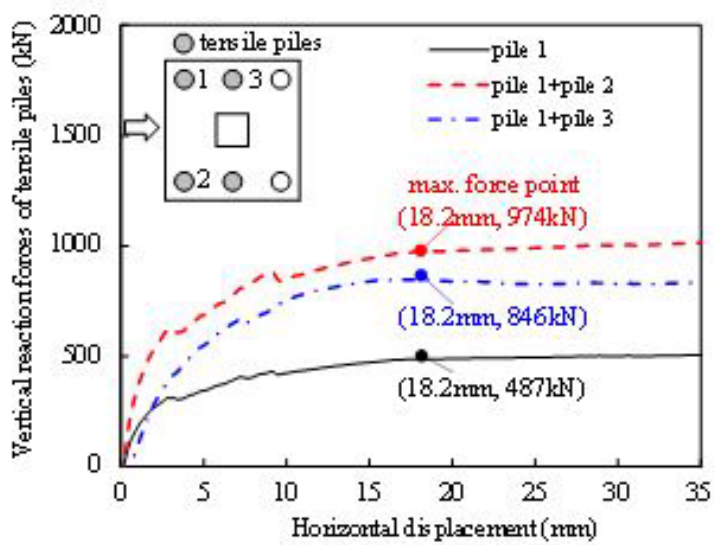

(d) $\mathrm{S} 2-2$

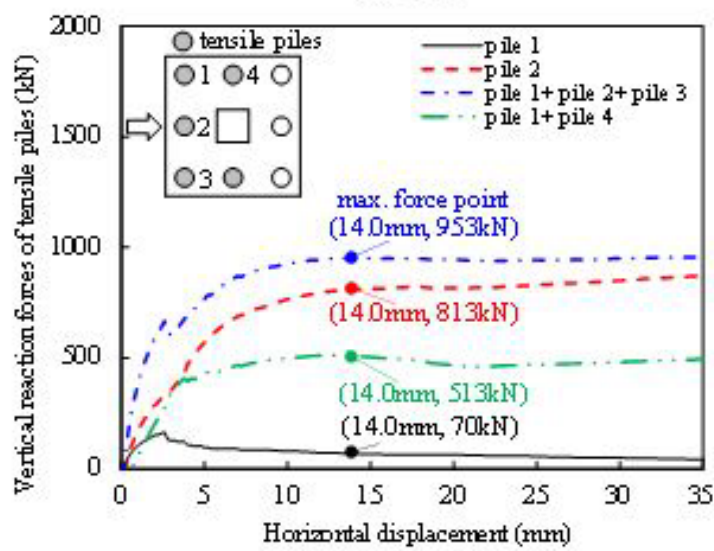

(f) $\mathrm{S} 2-4$ 


\subsubsection{Summary of the pile arrangement effect on the bending failure pattern of the footing}

Based on the above analysis results, the effect of pile arrangement on the footing bending failure pattern can be generally summarized, as shown in Figure 13. When the additional piles are placed at the center of the sides parallel to the loading direction ((1) and (4)), the extent of yielding of the top bars placed in the loading direction near the bending verification section is constrained. When the additional piles are placed at the center of the sides perpendicular to the loading direction ((2) and (3)), the extent of yielding of the top bars placed in the other direction is constrained. When the additional pile is placed at the center of the footing $((5))$, the extents of yielding of the top bars are constrained in two directions.

Thus, as shown in Figure 13, the bending failure pattern of the footing can be controlled by the pile arrangement. When the spacing of the tensile piles at the side perpendicular to the loading direction is properly adjusted ((2) and (3)), the main yielding of the footing is controlled to the top bars placed in the loading direction, near at the bending verification section, showing the similar bending failure pattern of beam as assumed in the design stage.

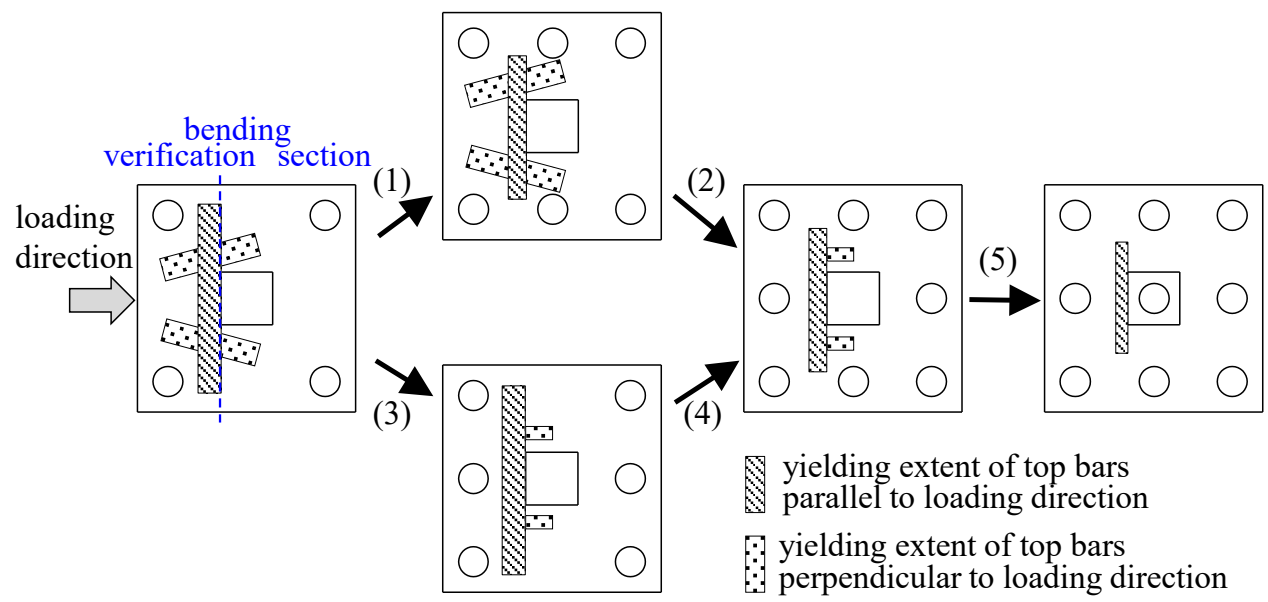

Figure 13: Change in extent of yielding of footing top bars with pile arrangement.

\section{Application condition of beam theory-based method to evaluate footing bending capacity considering pile arrangement effect}

When a footing can be assumed as beam member, the acting moment on the bending verification section calculated from pile reaction forces can be considered equal to the resisting moment, which can be obtained by stress integration over the whole section. After the top steel bars yield, the resisting moment on the bending verification section can be approximately calculated by the tensile forces of top steel bars timing footing effective height, without considering the resisting moment due to the tensile stress of concrete. Thus, by comparing the acting and resisting moments on the bending verification section, the application condition of the current beam theory-based method to accurately evaluate footing bending capacity can be investigated. The results are shown in Figure 14 for each case included in Series 1 and 2, respectively. 


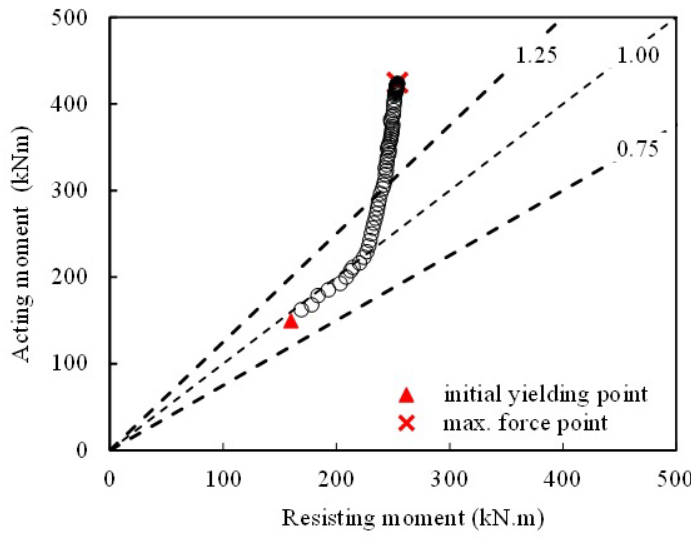

(a) S1-1

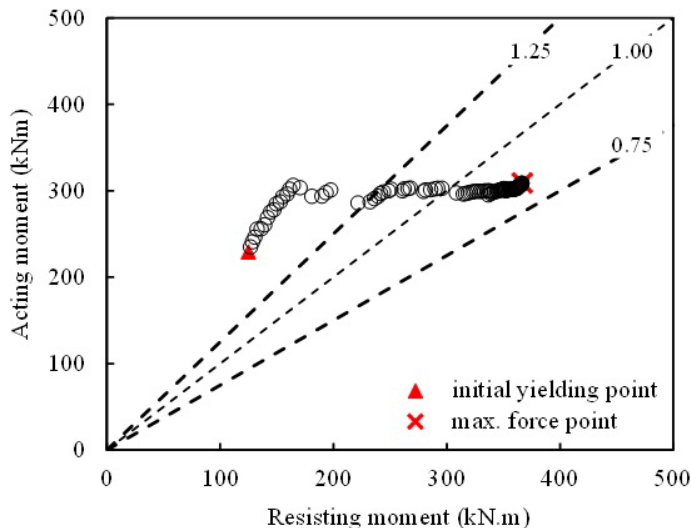

(c) S2-1

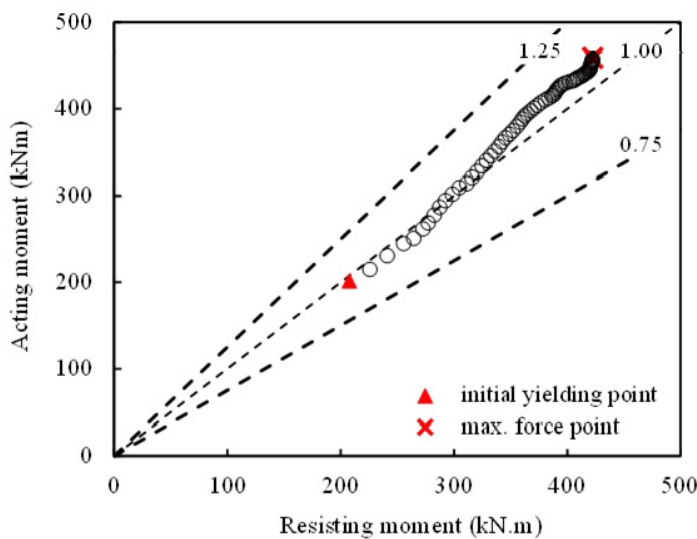

(e) $\mathrm{S} 2-3$

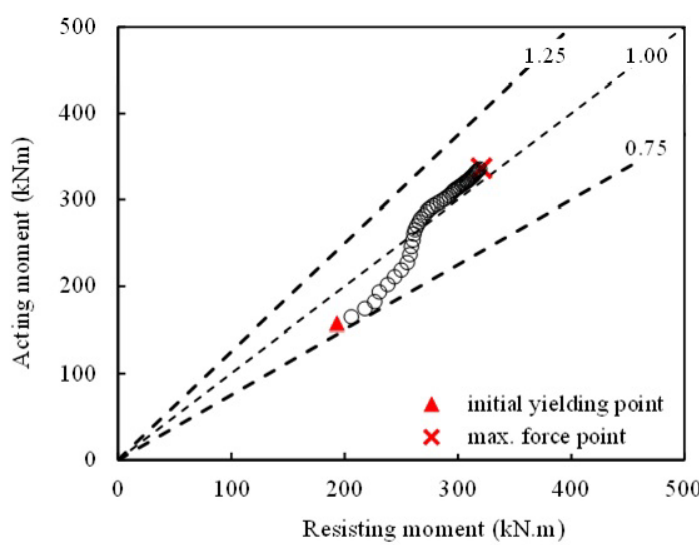

(g) $\mathrm{S} 2-5$

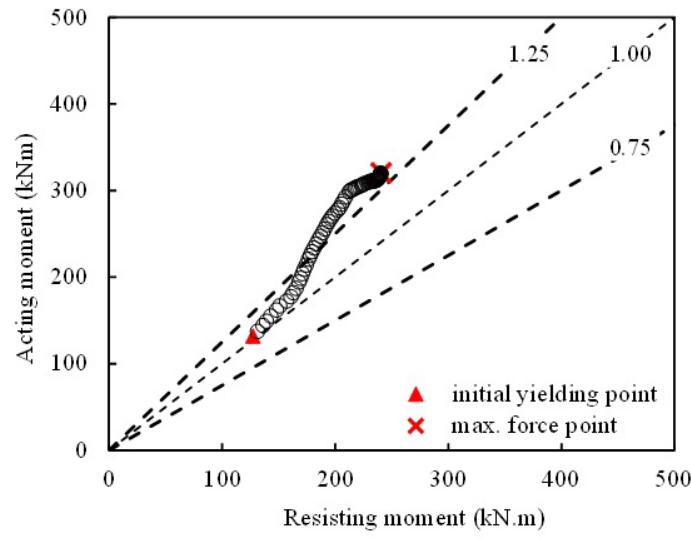

(b) $\mathrm{S} 1-2$

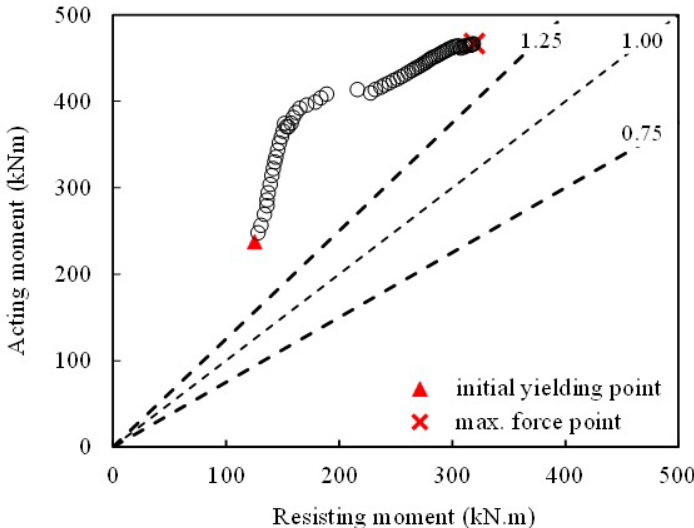

(d) $\mathrm{S} 2-2$

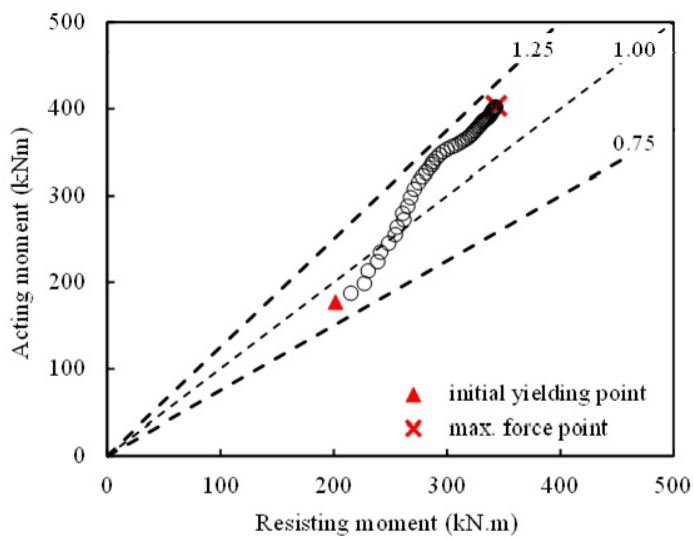

(f) $\mathrm{S} 2-4$

Figure 14: Acting and resisting moments on the bending verification section. 
In Case S1-1 of Series 1, except for the later stage near the maximum force point, in which the yielding of the top bars occurs within a large extent (Figure 11(a)), the acting moment is approximately equal to the resisting moment from the initial yielding point, showing that it is possible to apply the beam theory-based method to evaluate footing bending capacity. In Case S1-2, the acting moment has good agreement with the resisting moment between the initial yielding and maximum force points. In Series 2, except for Cases S2-1 and S2-2 with large yielding extent of top steel bars in two directions (Figure 11(c) and (d)), Cases S2-3 to S2-5 show a similar result to that of Series 1: it is possible to apply the beam theory-based method to accurately evaluate the footing bending capacity.

Comparing the pile arrangement of these cases, it is found that when additional piles are placed at the center of the sides perpendicular to the loading direction to obtain a small pile spacing, the yielding of the top bars perpendicular to the loading direction is effectively constrained, resulting in a similar bending failure pattern to that of beam and a good agreement between acting and resisting moments. Thus, it is possible to apply the beam theory-based method to accurately evaluate the bending capacity of a footing with proper pile spacing. In this research, the pile spacing is set to two and half times the pile diameter, according to the design standard (Japan Road Association, 2017).

\section{Conclusions}

Based on the basic FE model of the footing verified with the experimental results, a parametric analysis was carried out to investigate mainly the effect of pile arrangement on the bending failure pattern of a footing under lateral seismic loading. The application condition of the beam theory-based method to accurately evaluate the bending capacity of a footing is also discussed in terms of pile spacing. The major conclusions are as follows.

1. The FE model was verified with the experimental results to be able to accurately predict the overall behavior of a footing specimen under lateral seismic loading and can be used as the basic model for the parametric analysis related to pile arrangement effect.

2. After the point of initial yielding of top steel bars of footing, the pile arrangement can largely affect the horizontal rigidity of bridge pile foundation subjected to lateral seismic loading.

3. The pile arrangement can largely affect the bending failure pattern of a footing. The piles placed at the center of the sides parallel to the loading direction can constrain the extent of yielding of the top bars placed in the loading direction. Similarly, the piles placed at the center of the sides perpendicular to the loading direction can constrain the extent of yielding of the top bars placed in the other direction. The center pile of a footing can constrain the extent of yielding of the top bars in two directions.

4. The accuracy of the beam theory-based method to evaluate the footing bending capacity largely depends on the failure pattern. when the pile spacing of the sides perpendicular to the loading direction is two and half times the pile diameter, the extent of yielding can be controlled to mainly the top bars in the loading direction near the bending verification section, showing similar bending failure pattern of beam; the beam theory-based method has a high accuracy to evaluate the footing bending capacity.

In the near future, based on the analysis results presented in this paper, the pile arrangement effect on the bending failure pattern of a footing subjected to lateral seismic loading will be investigated by loading tests.

\section{Acknowledgements}

This study is supported by the project named "DEVELOPMENT OF SEISMIC TECHNOLOGY FOR STRENGTHENING EARTHQUAKE RESILIENCE OF INFRASTRUCTURE FACILITIES", conducted at the Public Works Research Institute of Japan from 2016 to 2021 . The support is gratefully acknowledged.

Author's Contribuitions: Conceptualization, Y Yang, T Masuda, and E Yoshida; Methodology, Y Yang, T Masuda, E Yoshida, and S Horiuchi; Investigation, Y Yang, T Masuda, E Yoshida, and S Horiuchi; Writing - original draft, Y Yang; Writing - review \& editing, Y Yang, T Masuda, E Yoshida, S Horiuchi, and T Kiriyama; Funding acquisition, T Kiriyama; Resources, T Kiriyama; Supervision, T Kiriyama.

Editor: Marcílio Alves. 


\section{References}

Adebar, P., Kuchma, D., Collins, M.P. (1990). Strut-and-tie models for the design of pile caps: an experimental study. ACl Structural Journal 87(1): 81-92.

Adebar, P., Zhou, L. (1996). Design of deep pile caps by strut-and-tie models. ACI Structural Journal 93(4): 437-448.

Ameli, M. J., Brown, D. N., Parks, J. E., Pantelides, C. P. (2016). Seismic column-to-footing connections using grouted splice sleeves. ACI Structural Journal 113(5): 1021-1030.

Bloodworth, A. G., Cao, J., Xu, M. (2012). Numerical modeling of shear behavior of reinforced concrete pile caps. Journal of Structural Engineering 138(6): 708-717.

Cao, J., Bloodworth, A. G., Xu, M. (2019). Efficient two-way shear grillage model solution for bridge RC four-pile caps under wall loading. Journal of Bridge Engineering 24(8): 04019071.

Casaburo, A., Petrone, G., Franco, F., De Rosa, S. (2019). A review of similitude methods for structural engineering. Applied Mechanics Reviews 71(3): 030802.

Chetchotisak, P., Yindeesuk, S., Teerawong, J. (2017).Interactive strut-and-tie-model for shear strength prediction of RC pile caps. Computers and Concrete 20(3):329-338.

Clarke, J.L. (1973). Behaviour and design of pile caps with four piles. Tech. Report No. 42_489. Wexham: Cement and Concrete Association.

Cornelissen, H., Hordijk, D., Reinhardt, H. (1986) .Experimental determination of crack softening characteristics of normal weight and lightweight. Heron, 31(2): 45-46.

Coutinho, C. P., Baptista, A. J., Rodrigues, J. D. (2016). Reduced scale models based on similitude theory: A review up to 2015. Engineering Structures 119: 81-94.

Feenstra, P. (1993). Computational aspects of biaxial stress in plain and reinforced concrete. PhD Dissertation. Delft University of Technology: Delft.

Grilli, D., Jones, R., Kanvinde, A. (2017). Seismic performance of embedded column base connections subjected to axial and lateral loads. Journal of Structural Engineering 143(5): 04017010.

Haber, Z. B., Saiidi, M. S., Sanders, D. H. (2014). Seismic performance of precast columns with mechanically spliced columnfooting connections. ACl Structural Journal 111(3): 639-650.

Hordijk, D. (1991). Local approach to fatigue of concrete. PhD Dissertation. Delft University of Technology: Delft.

Japan Road Association (2017). Design specifications of highway bridges: part IV Substructure. Tokyo, Japan: JRA (in Japanese).

Jensen, U.G., Hoang, L.C. (2012). Collapse mechanisms and strength prediction of reinforced concrete pile caps. Engineering Structures 35: 203-214.

Kappes, L., Berry, M., Murray, F., Stephens, J., Barnes, K. (2016). Seismic performance of concrete-filled steel tube to concrete pile-cap connections. Journal of Bridge Engineering 21(7): 04016042.

Kawashima, K., Unjoh, S. (1997). The damage of highway bridges in the 1995 hyogo-ken nanbu earthquake and its impact on japanese seismic design. Journal of Earthquake Engineering 1(3): 505-541.

Kosa, K., Fujii, Y., Kobayashi, K., Mizuta, K. (2000). Experimental study of footing effected by shear span ratio due to earthquake load. Journal of Structural Engineering 46A: 1405-1412 (in Japanese).

Kosa, K., Kobayashi, K., Fujii, Y., Mizuta, K. (1999). Experimental study of ultimate behavior of footing due to earthquake load. Journal of Structural Engineering 45A: 1369-1376 (in Japanese).

Park, J., Kuchma, D., Souza, R. (2008). Strength predictions of pile caps by a strut-and-tie model approach. Canadian Journal of Civil Engineering 35(12): 1399-1413.

Public Works Research Institute. (2015). Damage evaluation of bridge footings due to alkali silica reaction and repair/reinforcement approach. Technical Note, No. 4304. Tsukuba, Japan: PWRI (in Japanese).

Shama, A. A., Mander, J. B., Aref, A. J. (2002). Seismic performance and retrofit of steel pile to concrete cap connections. ACl structural journal 99(1): 51-61. 
Souza, R., Kuchma, D., Park, J., Bittencourt, T. (2009). Adaptable strut-and-tie model for design and verification of four-pile caps. ACl Structural Journal 106(2): 142-150.

Suzuki, K., Otsuki, K. Tsuchiya, T. (2001). Influence of edge distance on failure mechanism of pile caps. Transactions of the Japan Concrete Institute 22: 361-368.

Suzuki, K., Otsuki, K., (2002). Experimental study on corner shear failure of pile caps. Transactions of the Japan Concrete Institute 23: 303-310.

Suzuki, K., Otsuki, K., Tsubata, T. (1999). Influence of bar arrangement on ultimate strength of four-pile caps. Transactions of the Japan Concrete Institute 20: 195-202.

TNO DIANA BV (2018). DIANA User's Manual (https://dianafea.com/manuals/d102/Diana.html). TNO DIANA BV: Delft, The Netherlands.

Xiao, Y., Chen, L. (2013). Behavior of model steel H-pile-to-pile-cap connections. Journal of Constructional Steel Research 80 : 153-162.

Xiao, Y., Priestley, M.N., Seible, F. (1996). Seismic assessment and retrofit of bridge column footings. ACI Structural Journal 93(1): 79-94.

Xiao, Y., Wu, H., Yaprak, T. T., Martin, G. R., Mander, J. B. (2006). Experimental studies on seismic behavior of steel pile-to-pilecap connections. Journal of Bridge Engineering 11(2): 151-159.

Xiao, Y., Zhang, Z., Hu, J., Kunnath, S. K., Guo, P. (2011). Seismic behavior of CFT column and steel pile footings. Journal of Bridge Engineering 16(5): 575-586. 